\title{
Influence of the Belousov-Zhabotinsky substrate concentration on the lifetime and self-oscillating behavior of a polymer solution
}

\author{
Tomoka Nakazumi ${ }^{1}$ and Yusuke Hara ${ }^{1, a}$ \\ ${ }^{1}$ Research Institute for Sustainable Chemistry, ISC, National Institute of Advanced Industrial Science and Technology, AIST, Central 5-2, 1- \\ 1-1 Higashi, Tsukuba 305-8565, Japan.
}

\begin{abstract}
In this study, we synthesized a self-oscillating polymer chain with N-ethylacrylamide (NEAAm) as the main-chain. This exhibits a higher lower critical solution temperature than an $\mathrm{N}$-isopropylacrylamide main chain. We subsequently measured the transmittance self-oscillation of poly[NEAAm-co-Ru(bpy $\left.)_{3}\right]\left[R u(b p y)_{3}=4\right.$-vinyl-4'methyl-2,2'-bipyridinebis(2,2' bipyridine)bis(hexafluorophosphate) ruthenium] solutions comprising three BelousovZhabotinsky (BZ) substrates (malonic acid, sodium bromate, and sulfuric acid), under stirring at constant temperature. The soluble-insoluble self-oscillation of the polymer solution originated from the different solubility of the $\mathrm{Ru}(\mathrm{bpy})_{3}$ moiety as a catalyst of the $\mathrm{BZ}$ reaction in the reduced and oxidized states. We demonstrated that the self-oscillating behavior was significantly affected by the initial concentration of the sodium bromate. Moreover, we clarified that the lifetime of the transmittance self-oscillation can be predicted from the initial concentration of malonic acid.
\end{abstract}

\section{Introduction}

The use of the self-oscillating polymer chain copolymerized with 4-vinyl-4'-methyl-2,2'bipyridinebis (2,2'bipyridine)bis(hexafluorophosphate) ruthenium $\left[\mathrm{Ru}(\mathrm{bpy})_{3}\right]$ as a catalyst for the BelousovZhabotinsky (BZ) reaction [1-12] has been much investigated for application to soft actuators and soft robots with autonomous motion. The polymer chain is driven while consuming malonic acid, the energy source of the BZ reaction. This occurs because self-oscillating behavior is induced by a $\mathrm{BZ}$ reaction originating from the $\mathrm{Ru}(\mathrm{bpy})_{3}$ moiety in the polymer chain [13-22]. The BZ reaction has been much investigated and is a well-known oscillating reaction that causes spontaneous redox oscillation and a wide variety of nonlinear phenomena. In this reaction, an oxidant (sodium bromate) oxidizes an organic acid (malonic acid) in the presence of a metal catalyst $\left[\mathrm{Ru}(\mathrm{bpy})_{3}\right]$ that in turn undergoes periodical redox change. When the redox state of the metal catalyst changes, its solubility also changes simultaneously. In a previous study, polymer chains covalently bonded to $\mathrm{Ru}(\mathrm{bpy})_{3}$ were driven by making use of the periodical solubility change of the metal catalyst induced by the BZ reaction. This polymer solution, comprising three BZ substrates (malonic acid, sodium bromate, and sulfuric acid), undergoes transmittance self-oscillation. Thus, soluble-insoluble self-oscillations originate from the different solubilities of the $\mathrm{Ru}(b p y)_{3}$ moiety in the reduced and oxidized states. In a previous investigation, the main-chain of the self-oscillating polymer selected was poly(N-isopropylacrylamide) [poly(NIPAAm)] [15] which exhibits a lower critical solution temperature (LCST) of $\sim 32{ }^{\circ} \mathrm{C}$. As the $\mathrm{Ru}(\mathrm{bpy})_{3}$ was covalently bonded to the poly(NIPAAm), the LCST of poly[NIPAAm-co-Ru(bpy) $)_{3}$ in the reduced state was lower than that in the oxidized state because the reduced $\mathrm{Ru}(\text { bpy })_{3}$ moiety exhibited lower solubility compared to the oxidized $\mathrm{Ru}(\mathrm{bpy})_{3}$ moiety [15]. This difference in solubility originates from the transmittance selfoscillation induced by the $\mathrm{BZ}$ reaction. Hara et al. selected the self-oscillating polymer main-chain with the higher LCST to undergo self-oscillation in a wide range of temperature conditions $[23,24]$. In these studies, Nethylacrylamide (NEAAm) was adopted because of its high LCST compared to the poly(NIPAAm) chain; the LCST of poly[NEAAm-co-Ru(bpy) $)_{3}$ was $44{ }^{\circ} \mathrm{C}$ in the oxidized state and $16{ }^{\circ} \mathrm{C}$ in the reduced state. The difference in solubility of the poly[NEAAm-co-Ru(bpy $)_{3}$ ] in the reduced and oxidized states is attributed to the transmittance self-oscillation under constant temperature conditions.

Notably, it is important to establish the control factor of the period of the transmittance self-oscillation for application to soft actuators and soft robots. Thus, in this study, we examined the influence of the $\mathrm{BZ}$ substrate (sodium bromate and malonic acid) concentration in the polymer solutions on the period and transmittance selfoscillating behavior. Moreover, the duration of selfoscillation is also an important factor in the development of autonomous soft actuators and soft robots with a long life. Thus, we evaluated the influence of malonic acid concentration on the lifetime of the transmittance selfoscillation.

a Corresponding author: y-hara@aist.go.jp 


\section{Experimental section}

\subsection{Synthesis of poly[NEAAm-co-Ru(bpy $\left.)_{3}\right]$}

Poly[NEAAm-co-Ru(bpy) $)_{3}$ ] (Figure 1) was synthesized by random polymerization at $83{ }^{\circ} \mathrm{C}$ for $5 \mathrm{~h}$ under nitrogen bubbling. $\mathrm{Ru}(\mathrm{bpy})_{3}(1.25 \mathrm{~g})$ and NEAAm $(10.7 \mathrm{~g})$ monomers together with 2,2'-azobis(2methylbutyronitrile) (initiator, $0.63 \mathrm{~g}$ ) were dissolved in an ethanol/water $(1: 1 ; 125.3 \mathrm{~g})$ mixture. The resultant polymer mixture was subsequently dialyzed against ethanol for $10 \mathrm{~d}$.

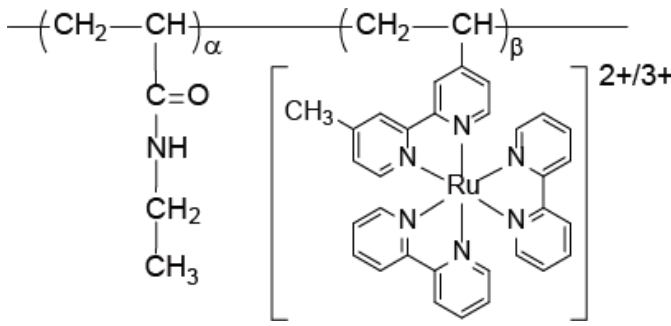

Figure 1. Chemical structure of the self-oscillating polymer chain $\{$ poly[NEAAm-co-Ru(bpy) 3$]\}$. NEAAm $=\mathrm{N}-$ ethylacrylamide; Ru(bpy) $3=4$-vinyl-4' - methyl-2,2' bipyridinebis $\left(2,2^{\prime}\right.$ bipyridine)bis(hexafluorophosphate) ruthenium.

\subsection{Measurement of transmittance self- oscillation of poly[NEAAm-co-Ru(bpy $)_{3}$ ]}

0.3 wt. $\%$ of poly[NEAAM-co-Ru(bpy $\left.)_{3}\right]$ aqueous solution comprising the three BZ substrates (malonic acid, sodium bromate, and sulfuric acid) were prepared to measure the transmittance self-oscillation. The selfoscillating behavior was detected by a spectrophotometer at $570 \mathrm{~nm}$ under constant stirring. This wavelength is the isosbestic point of the polymer solution in the reduced and oxidized states. The temperature of the polymer solution was fixed at $11{ }^{\circ} \mathrm{C}$ to detect stable selfoscillating behavior.

\section{Results and Discussion}

Figures 2 and 3 represent the transmittance selfoscillations of the poly[NEAAm-co-Ru(bpy) $)_{3}$ ] aqueous solution comprising fixed concentrations of the three BZ substrates at constant temperature $\left(11^{\circ} \mathrm{C}\right)$ under stirring. The large noise observed in these self-oscillating graphs was attributed to the carbon dioxide $\left(\mathrm{CO}_{2}\right)$ generated in the BZ reaction. As illustrated in Figure 2, the self-oscillating behavior was significantly affected by the initial concentration of the sodium bromate. The period of self-oscillation was much slower in Figure 2(A) than in 2(B), even though the difference in concentration was only $0.2 \mathrm{M}$. This trend indicated that the amount of sodium bromate is significantly important to control the transmittance self-oscillating behavior. Thus, we concluded that the oxidation process of $\mathrm{Ru}(\mathrm{bpy})_{3}$ in the $\mathrm{BZ}$ reaction is significantly affected by the concentration of the sodium bromate. Conversely, the influence of the initial concentration of malonic acid was smaller, at a fixed concentration $(0.5 \mathrm{M})$ of sodium bromate, [Figures 3(A) and 3(B)].
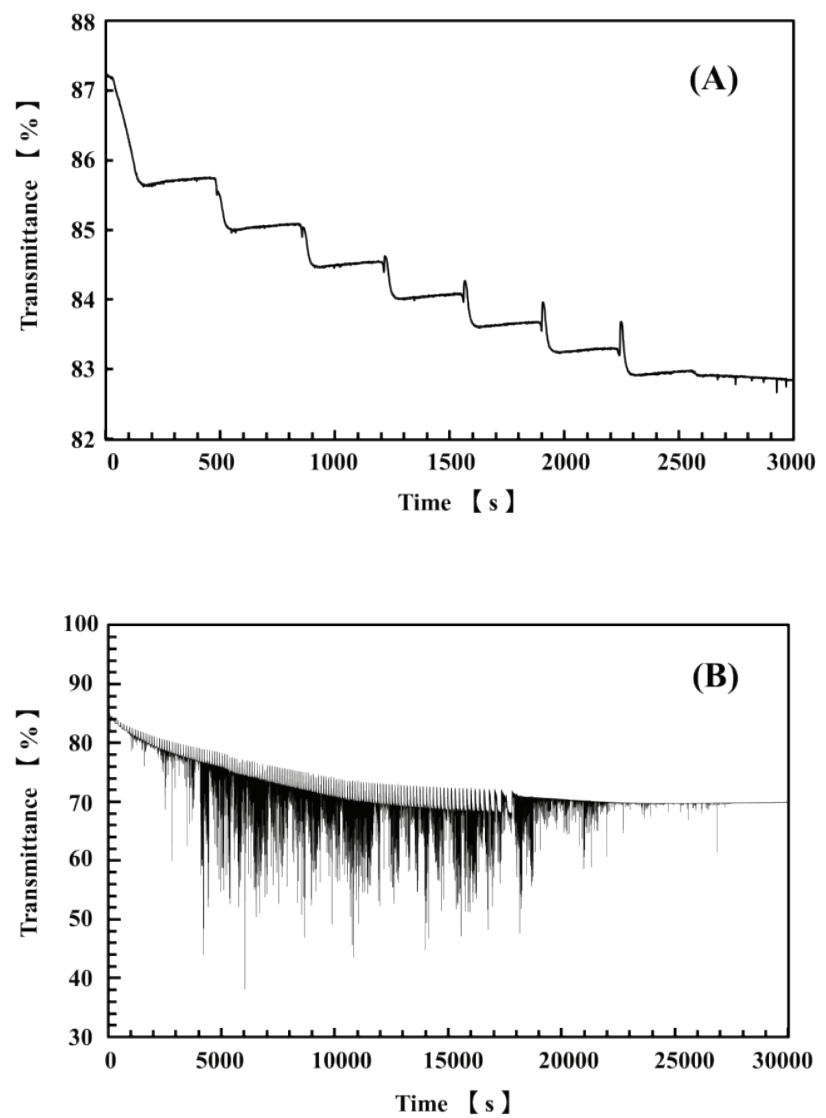

Figure 2. Transmittance self-oscillation profiles for a $0.3 \mathrm{wt}$ \% poly[NEAAm-co-Ru(bpy $)_{3}$ ] solution with fixed initial concentrations of malonic acid $(0.06 \mathrm{M})$ and sulfuric acid $(0.3$ $\mathrm{M}$ ); concentration of sodium bromate at (A) $0.1 \mathrm{M}$ and (B) 0.3 $\mathrm{M}$, at $11^{\circ} \mathrm{C}$. NEAAm $=\mathrm{N}$-ethylacrylamide; Ru(bpy $)_{3}=4$-vinyl4 '-methyl-2,2'-

bipyridinebis(2,2'bipyridine)bis(hexafluorophosphate) ruthenium.

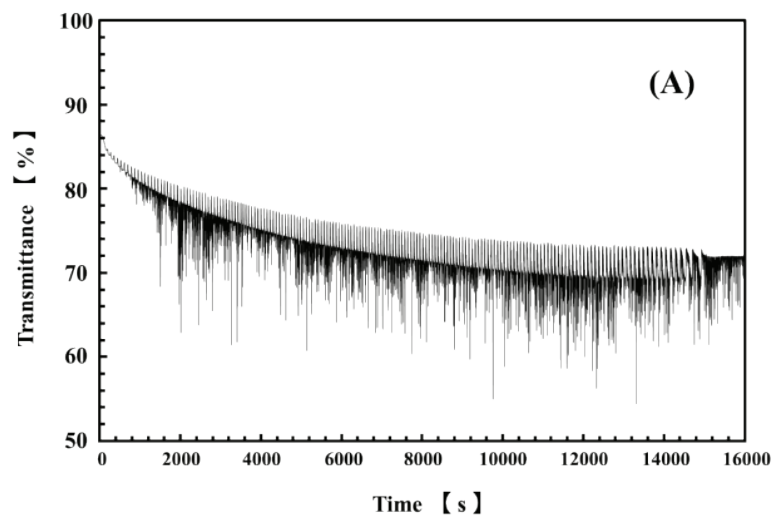




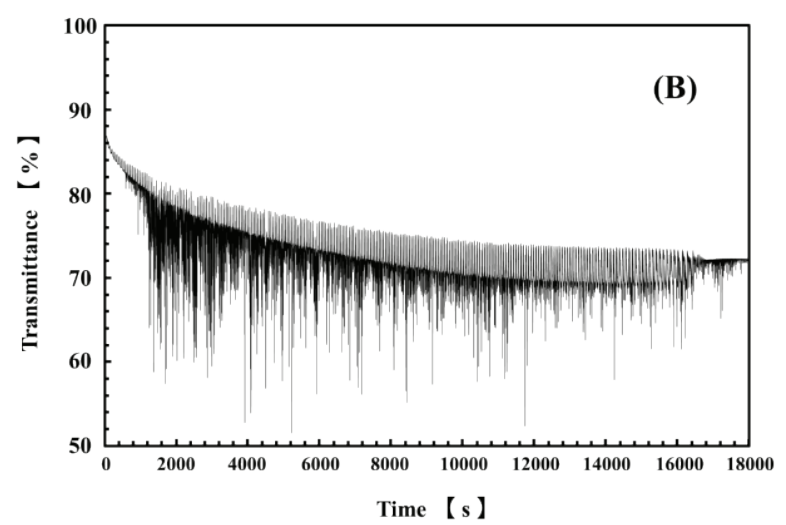

Figure 3. Transmittance self-oscillation profiles for a $0.3 \mathrm{wt} \%$ poly([NEAAm-co-Ru(bpy) 3 ] aqueous solution with fixed initial concentrations of sodium bromate $(0.5 \mathrm{M})$ and sulfuric acid $(0.3$ $\mathrm{M}$ ); concentrations of malonic acid at (A) $0.08 \mathrm{M}$ and (B) $0.1 \mathrm{M}$, at $11^{\circ} \mathrm{C}$. NEAAm $=$ N-ethylacrylamide; $\mathrm{Ru}(\mathrm{bpy})_{3}=4$-vinyl-4' methyl-2,2'-

bipyridinebis(2,2'bipyridine)bis(hexafluorophosphate) ruthenium.

Figure 4 illustrates the relationship between the initial substrate concentrations and the period of the transmittance self-oscillation of the poly[NEAAm-co$\mathrm{Ru}(\mathrm{bpy})_{3}$ ] aqueous solution. The period of the transmittance self-oscillation at an initial concentration of sodium bromate of $0.9 \mathrm{M}$ was approximately ten-fold smaller than that observed when the concentration was reduced to $0.1 \mathrm{M}$. This trend demonstrated that the period of self-oscillation could be highly accelerated by changing the sodium bromate concentration. On the other hand, as the initial concentration of malonic acid was changed, the changing range of the period was comparatively smaller. These results demonstrated that the initial concentration of sodium bromate is significantly effective in accelerating the period of the transmittance self-oscillation. An increase in the solution temperature has also been reported to have a significant effect [15].

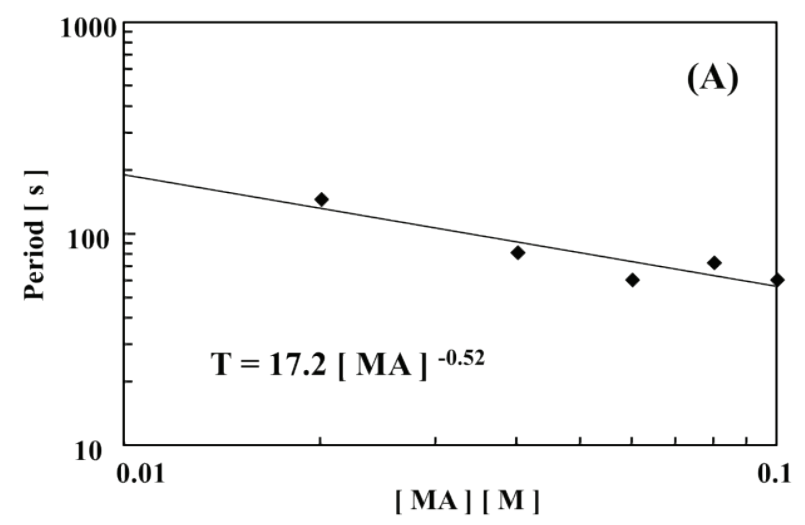

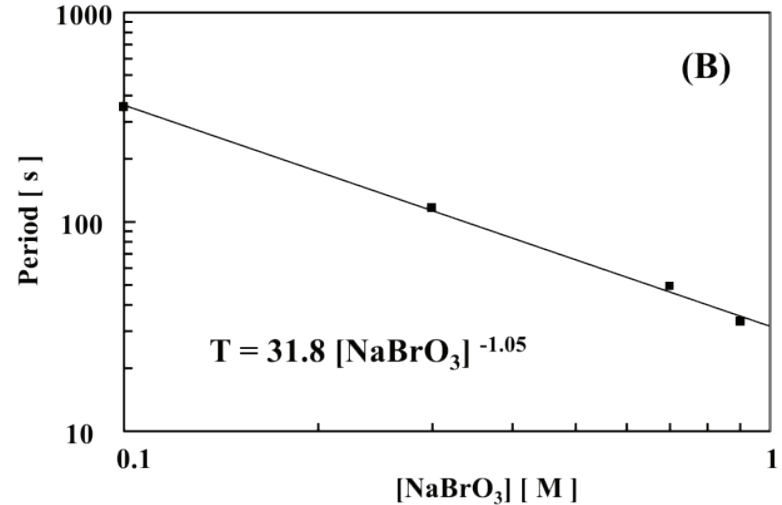

Figure 4. Logarithmic plots of period T (s) $v s$. initial molar concentration of one Belousov-Zhabotinsky (BZ) substrate at constant temperature $\left(11^{\circ} \mathrm{C}\right)$ under fixed concentrations for the other two BZ substrates: (A) sodium bromate $(0.5 \mathrm{M})$ and sulfuric acid $(0.3 \mathrm{M})$; $(\mathrm{B})$ malonic acid $(0.06 \mathrm{M})$ and sulfuric $\operatorname{acid}(0.3 \mathrm{M})$.

Figure 5 displays the lifetime of the transmittance selfoscillation of the poly[NEAAm-co-Ru(bpy $\left.)_{3}\right]$ aqueous solution at $11{ }^{\circ} \mathrm{C}$. The lifetime of the self-oscillation was found to be linearly related to the initial concentration of malonic acid. This demonstrated that the lifetime of the self-oscillation can be predicted from the initial concentration of malonic acid because the malonic acid is the energy source of the BZ reaction.

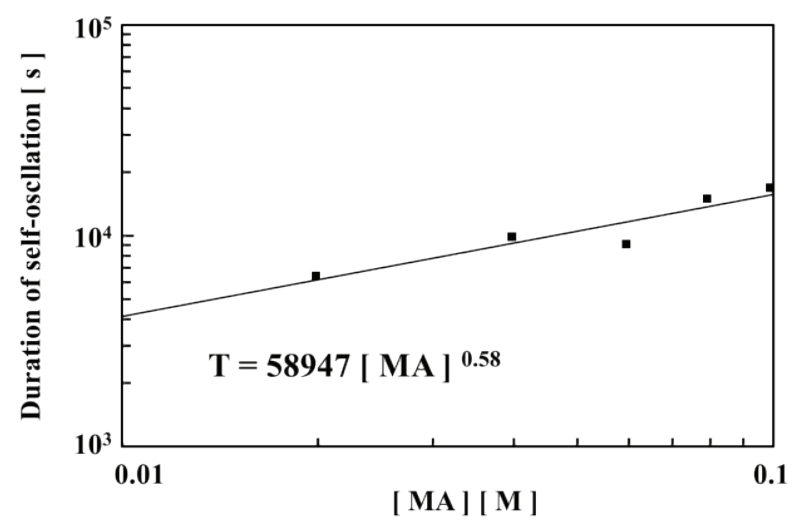

Figure 5. Lifetime of the transmittance self-oscillation for 0.3 wt. $\%$ poly[NEAAm-co-Ru(bpy) 3 ] solutions as a function of malonic acid concentration, with fixed initial concentrations of sulfuric acid $(0.3 \mathrm{M})$ and sodium bromate $(0.5 \mathrm{M})$, at $11^{\circ} \mathrm{C}$. NEAAm $=$ N-ethylacrylamide; Ru(bpy) $3=4$-vinyl $-4^{\prime}$ - methyl2,2'-bipyridinebis (2,2' bipyridine)bis(hexafluorophosphate) ruthenium.

\section{Conclusion}

In this study, transmittance self-oscillations of a polymer chain with a high LCST were measured by changing the initial concentration of malonic acid and sodium bromate to clarify the control factor of the period. This study demonstrated that the self-oscillating behavior of poly[NEAAm-co-Ru(bpy $)_{3}$ ] was significantly affected by 
the initial concentration of sodium bromate. We also established that the period of self-oscillation for the poly[NEAAm-co-Ru(bpy) $)_{3}$ ] aqueous solution can be determined from the initial concentrations of malonic acid and sodium bromate. In addition, we proved that the lifetime of the self-oscillation of the polymer chain can be predicted from the initial concentration of malonic acid.

\section{Acknowledgements}

This work was supported by Grants-in-Aid (KAKENHI) for Young Scientists (B) (16K17493, 15K18014) and Scientific Research (B) (17H03209, 15H03827). This work was also carried out under the auspices of the New Energy and Industrial Technology Development Organization (NEDO) of Japan under the Industrial Technology Research Grant Program in 2011.

\section{References}

1. B.P. Belousov, Sb. Ref. Radiat. Med. (Collections of Abstracts on Radiation Medicine, Medgiz, Moscow) 1, 145 (1959)

2. A.N. Zaikin, A.M. Zhabotinsky, Nature 225, 535 (1970)

3. R.J. Field, E. Koros, R.M. Noyes, J. Am. Chem. Soc. 94, 8649 (1972)

4. R.J. Field, R.M. Noyes, J. Chem. Phys. 60, 1877 (1974)

5. R.J. Field, R.M. Noyes, J. Am. Chem. Soc. 96, 2001 (1974)

6. G. Nicolis, I. Prigogine, Self-Organization in nonequilibrium systems (Wiley, New York, 27, 1977)

7. E.J. Reusser, R.J. Field, J. Am. Chem. Soc. 101, 1063 (1979)

8. J. Lindsay Oscillations and traveling waves in chemical systems (Eds. R.J. Field, M. Burger, Wiley, New York, 1985)

9. J.D. Murray, Mathematical biology (Springer-Verlag, Berlin, 1990)

10. S.K. Scott, Chemical chaos, $1^{\text {st }}$ ed. (Oxford University Press, Oxford, 1991)

11. I.R. Epstein, K. Showalter, J. Phys. Chem. 100, 13132 (1996)

12. I.R. Epstein, J.A. Pojman, An introduction to nonlinear chemical dynamics: oscillations, waves, patterns, and chaos (Oxford University Press, New York, 1998)

13. T. Ishiwatari, M. Kawagishi, M. Mitsuishi, J. Polym. Sci.: Polym. Chem. 22, 2699 (1984)

14. R. Yoshida, T. Takahashi, T. Yamaguchi, H. Ichijo, J. Am. Chem. Soc. 118, 5134 (1996)

15. Y. Hara, Y. Takenaka, Sens. 14, 1497 (2014)

16. Y. Hara, R. Yoshida, J. Phys. Chem. B 109, 9451 (2005)

17. Y. Hara, R. Yoshida, J. Chem. Phys. 128, 224904, (2008)

18. Y. Hara, R. Yoshida, J. Phys. Chem. B 112, 8427 (2008)
19. Y. Hara, R. Yoshida, Macromol. Rapid Commun. 30, 1656 (2009)

20. Y. Hara, R.A. Jahan, Polym. 3, 330 (2011)

21. Y. Hara, H. Mayama, Y. Yamaguchi, Y. Takenaka, R. Fukuda, J. Phys. Chem. B 117, 14351 (2013)

22. Y. Hara, Chemosens. 1, 3 (2013)

23. Y. Hara, Adv. Mater. Res. 941,1208 (2014)

24. Y. Hara, Adv. Mater. Res. 941, 1212 (2014) 